\title{
SERUM LEVEL OF A SOLUBLE FORM OF ENDOGLIN (CD105) IS DECREASED AFTER GOECKERMAN'S THERAPY OF PSORIASIS
}

\author{
David Pohl ${ }^{1}$, Ctirad Andrýs ${ }^{1}$,Lenka Borskä ${ }^{2}$,Zdeněk Fiala ${ }^{3}$,Květa Hamaková ${ }^{4}$,Karel Ettler ${ }^{4}$, Jan Krejsek ${ }^{1}$ \\ Charles University in Prague, Faculty of Medicine and University Hospital Hradec Králové, Czech Republic: Department \\ of Clinical Immunology and Allergy ${ }^{1}$, Department of Pathological Physiology ${ }^{2}$, Department of Hygiene and Preventive \\ Medicine ${ }^{3}$, Department of Dermatology and Venereology ${ }^{4}$
}

\begin{abstract}
Summary: Background. Goeckerman's therapy (GT) of psoriasis is based on daily application of pharmacy grade coal tar on affected skin with subsequent exposure to UV light. Disturbances in angiogenic activity are characteristic for the immunopathogenesis of psoriasis. The aim of study was to evaluate the influence of GT of psoriasis on proinflammatory and angiogenic activities expressed as changes in levels of endoglin (CD105). Methods. Serum levels of a soluble form of endoglin were measured in peripheral blood samples of 38 patients with psoriasis before and after therapy. Sixty three otherwise healthy blood donors serve as a control group. The efficacy of GT was expressed as changes in Psoriasis Area and Severity Index (PASI). Results. PASI score was significantly diminished by GT $(\mathrm{p}<0.001)$. Serum levels of soluble CD105 were significantly diminished after GT. The serum level of soluble CD105 dropped from $7.85 \pm 2.26 \mathrm{ng} / \mathrm{ml}$ before therapy to $7.01 \pm 1.71 \mathrm{ng} / \mathrm{ml}$ after therapy ( $\mathrm{p}=0.0002$ ). Compared to serum levels of soluble CD105 in healthy blood donors, serum levels of soluble CD105 in patients before GT were significantly higher $(\mathrm{p}<0.001)$ and remained elevated after therapy $(p<0.001)$. Angiogenic activity expressed as serum endoglin is diminished in patients with psoriasis treated by GT.
\end{abstract}

Key words: Psoriasis; Goeckerman's therapy; Angiogenesis; Endoglin; CD105

\section{Introduction}

The original Goeckerman's method of therapy (GT) of psoriasis, which is based on daily application of pharmacy grade coal tar to affected skin with subsequent exposure of the body surface to UV light, was introduced by William Goeckerman in 1925 (10). This therapy is still exploited worldwide with minimal modifications (12).

Psoriasis is one of the most frequent skin diseases affecting approximately $2.5 \%$ of the world's population. Psoriasis could be characterized from rather narrow point of view as a T-cell driven hyperproliferative keratinocyte disease (19). Regardless the fact, the most important role in psoriasis pathogenesis is given to specific immunity; there are numerous abnormalities in innate immunity as well. The presence of high levels of antimicrobial peptides in lesions was found. Two major families of skin antimicrobial peptides, defensins and cathelicidins, are present in psoriatic lesions. Especially, beta-defensin-2 (HBD-2), the first antimicrobial peptide discovered from human skin, is abundant in psoriatic plaques.

The typical feature of psoriasis is epidermal hyperproliferation, which is closely linked to very high angiogenic activity. This angiogenic activity is firmly established in psoriatic lesions (13). Highly sophisticated process of an- giogenesis is carefully regulated by numerous intimate cellto-cell contacts and humoral interactions involving cytokines, growth and differentiation factors, matrix metalloproteinases, tissue inhibitors of matrix metalloproteinases and various products of blood coagulation and fibrinolysis (5). The proangiogenic factors and inhibitory activities are tightly regulated and are in balance under physiological conditions (8). Neoangiogenesis is also an integral part of the immunopathogenesis of chronic inflammatory diseases such as rheumatoid arthritis and retinopathy $(13,16)$. Endoglin (CD105) is a proliferation-associated and hypoxia-inducible protein abundantly expressed in angiogenic endothelial cells. It is a transmembrane accessory receptor for transforming growth factor- $\beta$ (TGF- $\beta$ ) (11). Endoglin is essential during angiogenesis. Tangible evidence of its proangiogenic role comes from knockout studies in which CD105 null mice die in utero as a result of impaired angiogenesis (9). CD105 is able to be shed into the circulation, with elevated levels detected in patients with various types of cancer (21) or immunopathological disorders such as systemic sclerosis and rheumatoid arthritis (25).

Our research is principally focused on investigation of the impact of polyaromatic hydrocarbons present in coal tar used in Goeckerman's therapy on immune system. Psoriasis is serving as a clinical model for us. Several parame- 
ters of inflammation and angiogenesis have already been determined and published by our group $(4,1)$.

We found the enhanced presence of a soluble form of proangiogenic molecule endoglin in peripheral blood of patients with psoriasis. The inhibitory effect of Goeckerman's therapy on this proangiogenic factor was described in our study. Regarding to our experience, soluble endoglin seems to be a promising marker which could add relevant information to our research effort.

\section{Methods}

Altogether, 38 adult patients with chronic plaque form of psoriasis were enrolled to this study. The study was approved by the Ethics Committee of the University Hospital in Hradec Kralove. Informed written consent was obtained from each patient. Our study group consisted of 18 females and 20 males (average age: 43.4 years, range: 18-76 years). Sixty three otherwise healthy blood donors (31 female and 32 male, average age: 34.4 years, range: $19-56$ years) served as a control group.

In the course of GT coal tar ointment with $5 \%$ pharmaceutical grade coal tar (Pix Lithanthracis) was overnight applied on affected skin (10-75\% of total body surface) and removed in the morning by olive oil and water bath. Subsequently, patients were irradiated with UV light daily (source of UV radiation: filtered mercury lamp Chirana 397, Chirana, Czech Republic). The light beam density (dose) was controlled by Sola - Scope 2000 spectrometer (Solatell, UK).

The average intensity of UV radiation in distance of 100 $\mathrm{cm}$ in front of UV lamp was $134.45 \mu \mathrm{W} / \mathrm{cm}^{2}$ (wavelength $280-315 \mathrm{~nm}$ ) and $245.60 \mu \mathrm{W} / \mathrm{cm}^{2}$ (wavelength $315.5-400$ $\mathrm{nm})$. The daily doses of irradiation ranged from 0.8868 $\mathrm{mJ} / \mathrm{cm}^{2}$ (exposure 1 minute) to $17.736 \mathrm{~mJ} / \mathrm{cm}^{2}$ (20 minutes of irradiation). The duration of UV irradiation was individual, limited by skin erythema development (range 1-15 minutes). The average duration of therapy was 24 days (range: 12-30 days). The efficacy of Goeckerman's therapy was followed using PASI score (7). GT is ceased when $50 \%$ decrease of PASI is achieved.

The only patients treated for the first time with GT therapy were enrolled to our study. No further medications regarding psoriasis or influencing inflammatory reaction were administered to our patients. Patients who are enrolled to this study are followed by dermatologist. Personal and family history was taken. Patients were examined physically. Basic biochemical and hematological parameters including leukocytes and differential cell count were determined. Special emphasis was done regarding exposure to harmful chemical substances, smoking and exposure to polyaromatic hydrocarbons in food and indoor environment (coal burning). No patients suffering from psoriatic arthritis were enrolled to our study as this form is not indicated to GT. Psoriatic arthritis was excluded by the rheumatological consultant based on results of clinical, radiographic and serological examinations. No apparent diseases affecting vascular system were found in our patients.

Peripheral blood samples were collected before the start of GT and immediately after termination of treatment and evaluation of PASI score. Samples were allowed to clot and serum was obtained after sample centrifugation. Serum samples were stored frozen at $-20^{\circ} \mathrm{C}$. Repeated thawing and freezing of samples was avoided. Soluble form of endoglin in serum was assessed by sandwich ELISA using diagnostic kit manufactured by R\&D Systems (USA). The standard range of this kit is from 0.15 to $10 \mathrm{ng} / \mathrm{ml}$ and the minimum detectable dose is $0.007 \mathrm{ng} / \mathrm{ml}$. Samples $(50 \mu \mathrm{l})$ were examined neat in duplicates.

Statistical analysis of data was performed using MedCalc (Belgium) statistical software. Normal distribution of data was assessed. Student's paired and unpaired t-tests or Wilcoxon's test were used. Probability level less than 0.05 was considered as significant.

\section{Results}

All results are expressed as an average \pm 1 SD. Disease severity was significantly positively affected by Goeckerman's therapy. Good clinical response was achieved in all patients. Pre-therapy PASI scores of $19.22 \pm 7.49$ dropped to $8.85 \pm 6.29$ after therapy $(\mathrm{p}<0.001)$. No correlations between serum levels of both endoglin levels before (correlation coefficient $0.0191, \mathrm{p}>0.05$ ) and after therapy (correlation coefficient $-0.01216, p>0.05$ ) to disease activity expressed as PASI score were found. Serum levels of soluble endoglin were significantly diminished after Goeckerman's therapy. The serum level of soluble endoglin dropped from $7.85 \pm$ $2.26 \mathrm{ng} / \mathrm{ml}$ before therapy to $7.01 \pm 1.71 \mathrm{ng} / \mathrm{ml}$ after therapy ( $p=0.0002$, power of test: 0.984$)$ (Fig. 1).

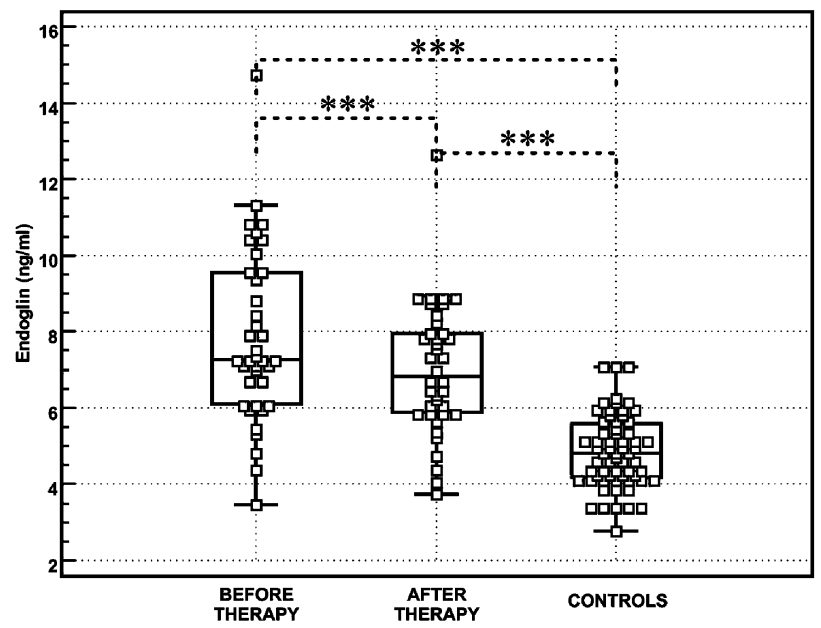

Fig. 1: The differences in the serum levels of soluble endoglin molecule $(\mathrm{ng} / \mathrm{ml})$ in patients with psoriasis before and after Goeckerman's therapy and comparison with healthy controls. A standard box-and-whisker plot (median, quartiles and range) was used. 
The control group consisted of 63 healthy blood donors (32 male and 31 female). Serum levels of soluble CD105 measured in control group were $4.88 \pm 0.95 \mathrm{ng} / \mathrm{ml}$. No differences were found between males and females $(p=0.7022)$. In comparison with serum levels of soluble endoglin in healthy blood donors, serum levels of soluble endoglin in patients before Goeckerman's therapy were relatively high ( $\mathrm{p}<$ $0.001)$ and remained elevated after therapy $(p<0.001)$.

\section{Discussion}

It is well established that Goeckerman's therapy of psoriasis (GT), which is based on the combination of antiinflammatory and immunomodulatory effects of poorly characterized aliphatic and aromatic hydrocarbons present in pharmaceutical grade coal tar and well documented immunosuppressive and immunomodulatory activities of UV irradiation, is highly efficient in the treatment of psoriasis. GT induces a good clinical response followed by a long term remission in a majority of patients (12).

This complex therapeutical regimen has numerous targets. The abnormal hyperproliferative capacity of epidermal cells is known to be diminished by this therapy (19). We found in our previous study significant decrease of serum levels of proangiogenic factors such as vascular endothelial growth factor VEGF and basic fibroblast growth factor bFGF during Goeckerman's therapy (2). Our present project addressed whether or not Goeckerman's therapy influences the serum level of proangiogenic protein endoglin in patients with psoriasis.

Recently, it was published by Arbiser et al. (3) that the carbazole in coal tar is the active antiangiogenic compound. In addition to its antiangiogenic activity, carbazole inhibited the production of IL-15 which is though to contribute to the immunopathogenesis of psoriasis by the recruitment of mononuclear cells.

Endoglin (CD105) is a coreceptor for transforming growth factor- $\beta$ and modulates TGF- $\beta$ signalling by interacting with TGF- $\beta$ receptors (11). The importance of endoglin in vascular morphogenesis is well established (15). Endoglin is predominantly expressed on endothelial cells. It is upregulated under inflammatory conditions as well as in skin lesions where endothelial cell proliferation occurs. Elevated expression of endoglin determined by immunohistochemical method in psoriatic plaques has already been described by van de Kerkhof et al. (23) and Rulo HFC el al. (18). Higher expression of endoglin was detected in psoriatic skin lesions whereas in uninvolved skin the expression of endoglin was low, than found in normal healthy skin. Similar results were reached using electron microscopic detection of endoglin in psoriatic lesions (24). Beside the membrane form, endoglin can occur in a soluble form, which is shed by membrane-type metalloproteinases into the circulation (22). Elevated levels of soluble CD105 are detected in various types of tumors, and in patients with various inflammatory diseases (25).
Information regarding the role of endoglin in angiogenesis is with a few exceptions based on investigation of membrane expressed molecule CD105. Data referred to the role of soluble form of endoglin are much sparse. Majority of them is derived from studies focused on neoangiogenesis associated with cancer (20). In the context of these studies, soluble form of endoglin is generally recognized as proangiogenic molecule. However, the unequivocal conclusion supporting this suggestion is still lacking $(21,14)$. Ultraviolet B irradiation (UVB) is an integral component of Goeckerman's therapy. Therapeutic benefit of GT is based on the synergistic effect of coal tar and UV irradiation. UV light with low intensity is sensitising skin thus enabling better penetration of immunomodulatory compounds from coal tar ointment into the skin. However, it has been reported that UVB could enhance cutaneous angiogenesis in an exposed skin. Several angiogenic factors, including VEGF and bFGF have been found to be upregulated after experimental UVB irradiation in the skin (6). Nevertheless, the intensity of UVB irradiation in the course of GT is relatively low probably with limiting proangiogenic potential. Our data describing significantly diminished serum levels of proangiogenic factor endoglin in patients with psoriasis after finishing GT is further supporting our opinion.

Angiogenesis is mandatory to support endometrial growth after menstruation and to provide a vascularized, receptive endometrium for implantation and placentation (17). Unfortunately, the data relevant to the menstruation cycle are lacking in our investigated group of patients.

\section{Conclusion}

In conclusion, we found that the serum level of endoglin (soluble CD105) which is increased in patients with psoriasis is significantly decreased after Goeckerman's therapy. We propose serum level endoglin as a promising marker of proangiogenic activity in patients suffering from psoriasis.

\section{Acknowledgment}

This study was supported by Ministry of Health, Czech Republic, Research project MZO 00179906 and by Ministry of Education, Czech Republic project No. MSM 0021620812.

\section{References}

1. Andrys C, Borska L, Pohl D, et al. Goeckerman's therapy for psoriasis with special reference to serum pentraxin 3 level. Int J Dermatol 2008;47:1011-1014.

2. Andrys C, Borska L, Pohl D, Fiala Z, Hamakova K, Krejsek J. Angiogenic activity in patients with psoriasis is significantly decreased by Goeckerman's therapy. Arch Dermatol Res 2007;298:479-483.

3. Arbiser JL, Govindarajan B, Battle TE, et al. Carbazole is a naturally occurring inhibitor of angiogenesis and inflammation isolated from antipsoriatic coal tar. J Invest Dermatol 2006;126:1396-1402.

4. Borska L, Fiala Z, Krejsek J, et al. Immunologic changes in TNF-alpha, sE-selectin, sP-selectin, sICAM-1, and IL-8 in pediatric patients treated for psoriasis with the Goeckerman's regimen. Pediatr Dermatol 2007;24:607-612.

5. Bhushan M, Young HS, Brenchley PEC, et al. Recent advances in cutaneous angiogenesis. Br J Dermatol 2002;147:418-425. 
6. Bielenberg DR, Bucana CD, Sanchez R, et al. Molecular regulation of UVB-induced cutaneous angiogenesis. J Invest Dermatol 1998;111:864-872.

7. De Rie MA, Goedkoop AY, Bos JD. Overview of psoriasis. Dermatol The 2002; 17:341-349.

8. Distler JH, Hirth A, Kurowska-Stolarska M, et al. Angiogenic and angiostatic factors in the molecular control of angiogenesis. Q J Nucl Med 2003:47:149-161.

9. Duff SE, Li Ch, Garland JM, Kumar S. CD105 is important for angiogenesis: evidence and potential applications. FASEB J 2003;17:984-992.

10. Goeckerman WH. Treatment of psoriasis. Northwest Med 1925;24:229-231.

11. Lebrin F, Goumans MJ, Jonker L, et al. Endoglin promotes endothelial proliferation and TGF-beta/ALK1 signal transduction. The EMBO Journal 2004;23 4018-4028.

12. Lebwohl M, Ali S. Treatment of psoriasis. Part 1. Topical therapy and phototherapy. J Am Acad Dermatol 2001:45:487-498.

13. Leong TT, Fearon U, Veale DJ. Angiogenesis in psoriasis and psoriatic arthritis: clues to disease pathogenesis. Curr Rheumatol Rep 2005;7:325-329.

14. Li Ch, Guo B, Wilson PB, et al. Plasma levels of soluble CD105 correlate with metastasis in patients with breast cancer. Int J Cancer (Pred. Oncol.) 2000;89: $122-126$.

15. Li DY, Sorensen LK, Brooke BS, et al. Defective angiogenesis in mice lacking endoglin. Science 1999;284:1534-1537.

16. Nielsen HJ, Christensen IJ, Svendsen MN, et al. Elevated plasma levels of vascular endothelial growth factor and plasminogen activator inhibitor-1 decrease during improvement of psoriasis. Inflamm Res 2002;51:563-567.

17. Punyadeera C, Thijssen VL, Tchaikovski S, et al. Expression and regulation of vas- cular endothelial growth factor ligands and receptors during menstruation and post-menstrual repair of human endometrium. Mol Hum Reprod 2006;12: $367-375$

18. Rulo HFC, Westphal JR, van de Kerkhof PCM, de Waal RMW, van Vlijmen IMJJ, Ruiter DJ. Expression of endoglin in psoriatic involved and uninvolved skin. J Dermatol Sci 1995;10:103-109.

19. Sabat R, Philipp S, Hoflich C, et al. Immunopathogenesis of psoriasis. Exp Dermatol 2007;16:779-798.

20. Smolej L, Andrys C, Maisnar V, et al. Plasma concentrations of vascular endothelial growth factor and basic fibroblast growth factor in lymphoproliferative disorders. Acta Medica 2005;48:57-58.

21. Takahshi N, Kawanishi-Tabata R, Haba A, et al. Association of serum endoglin with metastasis in patients with colorectal, breast, and other solid tumors, and suppressive effect of chemotherapy on the serum endoglin. Clin Cancer Res 2001;7:524-532.

22. Ten Dijke P, Goumans MJ, Pardali E. Endoglin in angiogenesis and vascular diseases. Angiogenesis 2008;11:79-89.

23. Van de Kerkhof PC, Rulo HF, van Pelt JP, van Vlijmen-Willems IM, De Jong EM. Expression of endoglin in the transition between psoriatic uninvolved and involved skin. Acta Derm Venereol 1998;78:19-21.

24. Westphal JR, Willems HW, Schalkwijk CJM, Ruiter DJ, de Waal RMW. A new 180-kDa dermal endothelial cell activation antigen: in vitro and in situ characteristics. J Invest Dermatol 1993;100:27-34

25. Wipff J, Avouac J, Borderie D, et al. Disturbed angiogenesis in systemic sclerosis: high levels of soluble endoglin. Rheumatology (Epub ahead of print), 2008.

Received: 08/07/2010. Accepted in revised form: 18/01/2011.

\section{Corresponding author:}

Dr. Ctirad Andrýs, Department of Clinical Immunology and Allergy, Charles University in Prague, Faculty of Medicine in Hradec Králové, Sokolská 581, 50005 Hradec Králové, Czech Republic; e-mail: andrys@lfhk.cuni.cz 